\title{
A new system for assessing atelectasis on chest $x$-ray after sternotomy for cardiac surgery
}

\author{
Rachael L. Parke ${ }^{1,3^{*}}$, Shay P. McGuinness ${ }^{1 \dagger}$, David Milne ${ }^{3 \dagger}$ and Andrew Jull ${ }^{3,4+}$ \\ *Correspondence: rparke@adhb.govt.nz

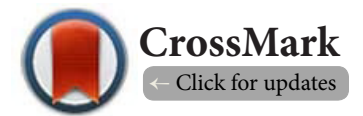 \\ ${ }^{\dagger}$ These authors contributed equally to this work. \\ ${ }^{1}$ Cardiothoracic \& Vascular Intensive Care Unit, Auckland City Hospital, Auckland, New Zealand. \\ 2Department of Radiology, Auckland City Hospital, Auckland, New Zealand. \\ ${ }^{3}$ School of Nursing, The University of Auckland, New Zealand. \\ ${ }^{4}$ National Institute of Health Innovation, University of Auckland, New Zealand.
}

\begin{abstract}
Background: Pulmonary atelectasis is common following sternotomy for cardiac surgery. The degree of atelectasis present on chest $\mathrm{x}$-ray has been used to assess efficacy of interventions designed to reduce atelectasis, however radiological atelectasis scoring systems used may exaggerate the clinical effect of atelectasis in these patients. We have produced an alternative scoring system that seeks to correct this problem and this study aimed to evaluate this.

Methods: Following ethics approval we retrospectively selected 50 consecutive patients admitted to the intensive care unit following cardiac surgery. Electronic copies of chest x-ray taken on return to the intensive care unit, on day 1 and day 3 postoperative were obtained and corresponding details of oxygenation were collected from patient records. Anonymised chest x-ray's were scored, using both the old and new scoring system, by a radiologist blinded to the clinical data. Chest x-ray scores were compared with oxygenation indices at the time of chest x-ray. Day 1 scores were also assessed for their ability to reflect day 3 oxygenation indices and supplemental oxygen requirement.

Results: The new score demonstrated better ability to detect atelectasis on chest x-ray and better specificity than the old score when comparing the chest $\mathrm{x}$-ray findings with the clinical oxygenation status of the patients. The new score also performed better at predicting day 3 oxygenation status from the day 1 chest $x$-ray.

Conclusions: This new scoring method performed better as an outcome measure for atelectasis in studies of patients following cardiac surgery. It may also better identify patients who require ongoing administration of supplemental oxygen on postoperative day 3.

Keywords: Atelectasis, cardiac surgery, cardiopulmonary bypass, chest x-ray, outcome measures
\end{abstract}

\section{Introduction}

Postoperative complications following cardiac surgery increase mortality, morbidity and costs [1]. One major cause of postoperative respiratory complications is atelectasis [2]. The development of atelectasis following general anaesthesia and cardiac surgery is almost inevitable $[2,3]$ and has been described as present in most patients with an incidence of around $90 \%$ of cardiac surgical patients $[4,5]$. Atelectasis impairs oxygenation, worsens lung compliance, augments the development of lung injury and increases pulmonary vascular resistance [6]. It may also be associated with postoperative infective complications such as pneumonia, [7] and may be resistant to simple techniques employed to improve lung function such as patient positioning, physiotherapy and incentive spirometry [3]. Ensuring adequate oxygenation and respiratory support is vital in the postoperative period; however there is little published evidence to guide clinicians in the objective selection and use of oxygen delivery devices [8]. We are conducting a large scale randomised controlled trial to assess the effect of prophylactic nasal high flow oxygen therapy (NHF) using the Optiflow $^{\mathrm{TM}}$ system (Fisher \& Paykel Healthcare, New Zealand) on postoperative oxygenation in cardiac surgical patients [9]. In order to evaluate the hypothesis that NHF can improve pulmonary function and reduce atelectasis we required a validated atelectasis scoring system. Currently there are few scoring systems for reporting atelectasis from chest $x$-rays [10-12]. The Radiological Atelectasis Score (RAS) has been used to describe the degree of atelectasis in postoperative patients [10]. We felt this score may over-emphasise subtotal atelectasis in the lower lobes and furthermore it does not attribute any extra weight if there is additional atelectasis in the middle or upper lobes. Therefore we have designed a new scoring system to differentiate the severity of atelectasis in patients with multi-lobar involvement.

The aims of this study were to evaluate a proposed atelectasis scoring system against a previously published scoring system in a group of patients following cardiac surgery; to assess the ability of the two scores to reflect the oxygenation at the time the chest 
Parke et al. Medical Imaging and Radiology 2014,

http://www.hoajonline.com/journals/pdf/2054-1945-2-2.pdf

doi: 10.7243/2054-1945-2-2

x-ray (CXR) was taken; and to assess the ability of the two scoring systems to reflect oxygenation indices on subsequent days.

\section{Methods}

Fifty consecutive patients' clinical records were selected for retrospective review. These patients were selected by the principal investigator and were admitted to the intensive care unit (ICU) during the month of January 2010. Inclusion criteria were: aged 18 years or more, received median sternotomy for cardiac surgery with cardiac bypass, weaned from mechanical ventilation and extubated within eight hours post-op, length of stay in ICU less than 24 hours, and only required simple nasal prongs or face mask for oxygen delivery following extubation. Ethical approval for the study was obtained from the Northern $X$ regional ethics committee. Due to the retrospective observational nature of the study, the need for informed consent was waived.

\section{Oxygenation indices}

Clinical details of oxygenation on post-operative day 1 and 3 were obtained from the patients' records and electronic copies of anteroposterior CXR taken on return to ICU (baseline), day 1 (d1) post-operative and day 3 (d3) post-operative were downloaded and stored on compact disc for review by the radiologist.

On day 1 all patients had arterial blood gas measurements available and the partial pressure of oxygen $\left(\mathrm{PaO}_{2}\right)$ and fraction of inspired oxygen $\left(\mathrm{FiO}_{2}\right)$ closest to the time the CXR was taken were recorded, along with pulse oximetry readings. Arterial blood gas measurements were not available on patients on day 3, so pulse oximetry was used to measure peripheral oxygen saturation $\left(\mathrm{SpO}_{2}\right)$ value. Oxygen requirement at time of $\mathrm{CXR}$ was recorded. From these data the $\mathrm{PaO}_{2} / \mathrm{FiO}_{2}(\mathrm{P} / \mathrm{F})$ and $\mathrm{SpO}_{2} / \mathrm{FiO}_{2}(\mathrm{~S} / \mathrm{F})$ ratios were calculated. An S/F ratio of 445 was selected as a binomial outcome to distinguish patients either requiring oxygen or with $\mathrm{SaO}_{2}$ or $\mathrm{SpO}_{2}<94 \%$ versus those with an $\mathrm{SaO}_{2}$ or $\mathrm{SpO}_{2} \geq 94 \%$ on air.

\section{Atelectasis scoring}

The x-rays were scored using both the radiological atelectasis score (RAS) and a modified radiological atelectasis score (m-RAS) system by a single radiologist (Author DM) who was blinded to the oxygenation data and to the order in which the $\mathrm{x}$-rays were taken by obscuring the date the CXR was taken (see box 1).

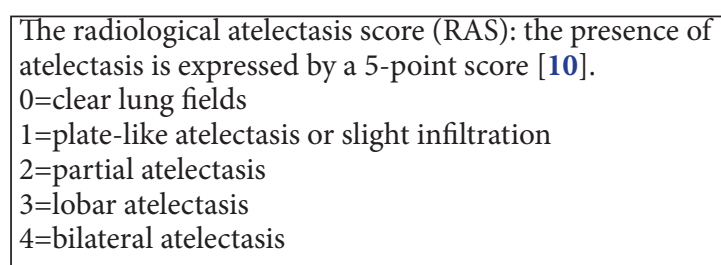

Data analysis

Data analysis was undertaken using STATA12 (StataCorp LP,
Texas, USA) and Statistical Package R (R Development Core Team (2010). R: A language and environment for statistical computing. R Foundation for Statistical Computing, Vienna, Austria. ISBN 3-900051-07-0, URL http://www.r-project.org/). For both the old and new scores the day 1 and day 3 CXR scores were also compared with oxygenation indices (P/F or S/F ratio) at the time of CXR. Day 1 scores were also assessed for their ability to characterize day $3 \mathrm{~S} / \mathrm{F}$ ratios below 445 (An S/F ratio of $<445$ equates to any requirement for supplemental oxygen or $\mathrm{SpO} 2<94 \%$ on air).

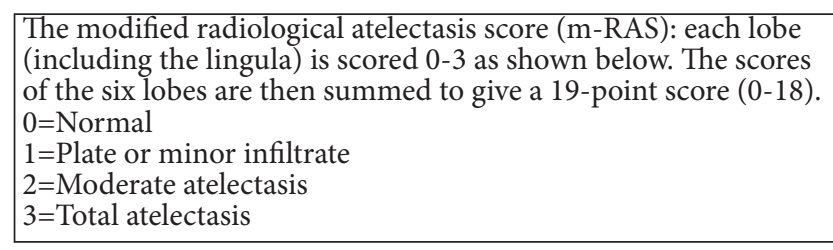

\section{Results}

Fifty patients were included in this study. Baseline demographic data is presented in (Table 1).

Table 1. Baseline demographics.

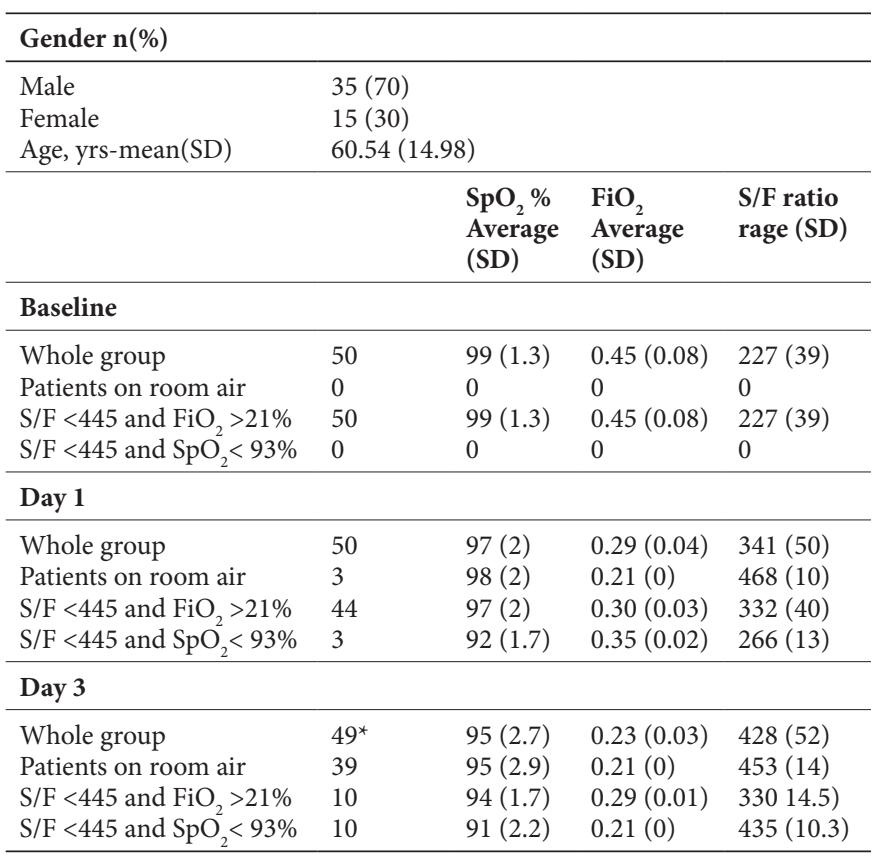

*One patient did not have data recorded on day 3 .

On post-operative return to the ICU, 43 patients (86\%) were determined to have some degree of atelectasis using both scoring systems. By day 1 the overall incidence of atelectasis was $86 \%$ using RAS and $98 \%$ using $m$-RAS. The incidence on day 3 was $98 \%$ using RAS compared with $96 \%$ using m-RAS. (Figure 1) shows the degree of atelectasis at return to ICU, day 1 and day 3 for the group. There was an approximately linear relationship between the RAS and m-RAS scores, but with $\mathrm{m}$-RAS demonstrating a greater range of scores. 
Parke et al. Medical Imaging and Radiology 2014,

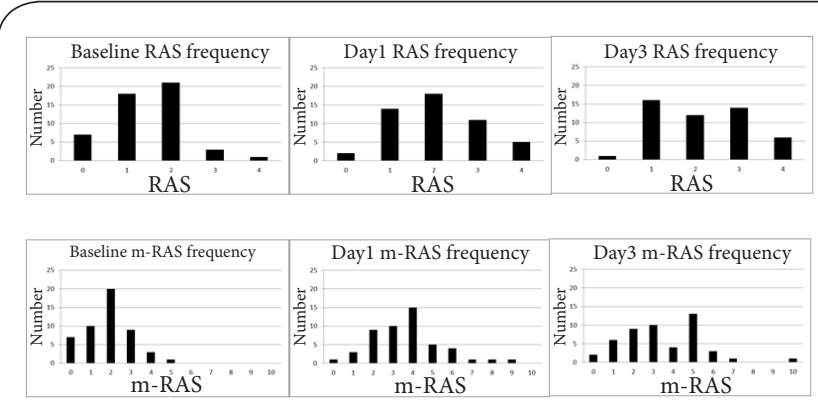

Figure 1. Frequency of RAS and m-RAS at baseline and day 1.

When comparing the scoring systems' ability to predict oxygenation status at day 3 from the changes seen on the CXR taken on day 1 , the m-RAS performed better than the RAS; both scoring systems were more accurate in reflecting day 3 oxygenation status from changes seen on the day 1 CXR than on the day 3 CXR. The ability of day 1 x-ray to predict day 3 oxygenation is shown in (Table 2). This was the only significant result with a likelihood ratio of 0.1 for an $\mathrm{m}$-RAS of 3 .

(Figure 2) shows the receiver operating characteristic (ROC) curves for using the two scores to predict whether the S/F ratio would be below 445 on day 3 using the baseline x-ray. The area under the curve for m-RAS is 0.62 and for RAS is 0.55 . (Figure 3 ) shows the ROC curves for using RAS and m-RAS on day 1 to predict an S/F ratio $<445$ on day 3 . The area under

Table 2. Ability of Day $1 \mathrm{~m}$-RAS to predict $\mathrm{S} / \mathrm{F}$ ratio $<445$ on day 3.

\begin{tabular}{lllllll}
\hline & Sensitivity & Specificity & PPV & NPV & LR+ & LR- \\
\hline $\mathrm{m}-\mathrm{RAS}>=0$ & $100 \%$ & $0 \%$ & 0.41 & -- & 1.0 & -- \\
$\mathrm{m}-\mathrm{RAS}>=1$ & $100 \%$ & $3.45 \%$ & 0.42 & 1.0 & 1.031 & 0.0 \\
$\mathrm{~m}-\mathrm{RAS}>=2$ & $100 \%$ & $13.8 \%$ & 0.44 & 1.00 & 1.1 & 0.0 \\
$\mathrm{~m}-\mathrm{RAS}>=3$ & $95 \%$ & $41.4 \%$ & 0.53 & 0.92 & 1.6 & 0.1 \\
$\mathrm{~m}-\mathrm{RAS}>=4$ & $75 \%$ & $62 \%$ & 0.58 & 0.78 & 2 & 0.4 \\
$\mathrm{~m}-\mathrm{RAS}>=5$ & $45 \%$ & $93 \%$ & 0.82 & 0.71 & 6.4 & 0.6 \\
$\mathrm{~m}-\mathrm{RAS}>=6$ & $30 \%$ & $100 \%$ & 1.0 & 0.67 & -- & 0.7 \\
$\mathrm{~m}-\mathrm{RAS}>=7$ & $15 \%$ & $100 \%$ & 1.0 & 0.63 & -- & 0.9 \\
$\mathrm{~m}-\mathrm{RAS}>=8$ & $10 \%$ & $100 \%$ & 1.0 & 0.62 & -- & 0.9 \\
$\mathrm{~m}-\mathrm{RAS}>=9$ & $5 \%$ & $100 \%$ & 1.0 & 0.6 & -- & 1.0 \\
$\mathrm{~m}-\mathrm{RAS}>9$ & $0 \%$ & $100 \%$ & -- & 0.59 & -- & 1.0 \\
\hline
\end{tabular}

the curve for m-RAS is 0.79 and for RAS is 0.71 .

When analyzing the oxygenation indices it was found that on day $341 \%$ of patients had an S/F ratio below 445 , indicating either an ongoing requirement for supplemental oxygen therapy $(\mathrm{n}=10)$ or a measured $\mathrm{SpO}_{2}$ of $\leq 93 \%$ on room air $(n=10)$. In the group still requiring supplemental oxygen, the average $\mathrm{SpO}_{2}$ was $94.3 \%$ (range $91-96 \%$ ), while receiving an average $\mathrm{FiO}_{2}$ of 0.28 (giving an average $\mathrm{S} / \mathrm{F}$ ratio of 330 ).

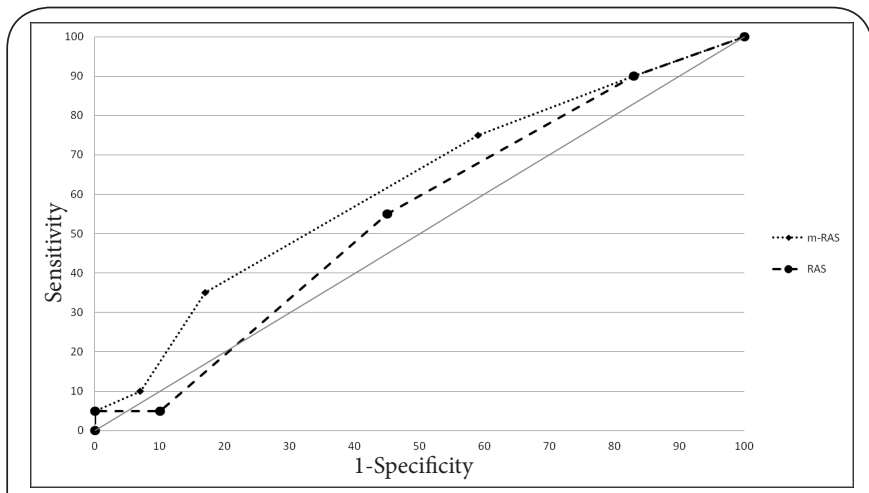

Figure 2. ROC curve for predicting day $3 \mathrm{~S} / \mathrm{F}$ ratio of $<445$ using baseline $\mathrm{x}$-ray scores.

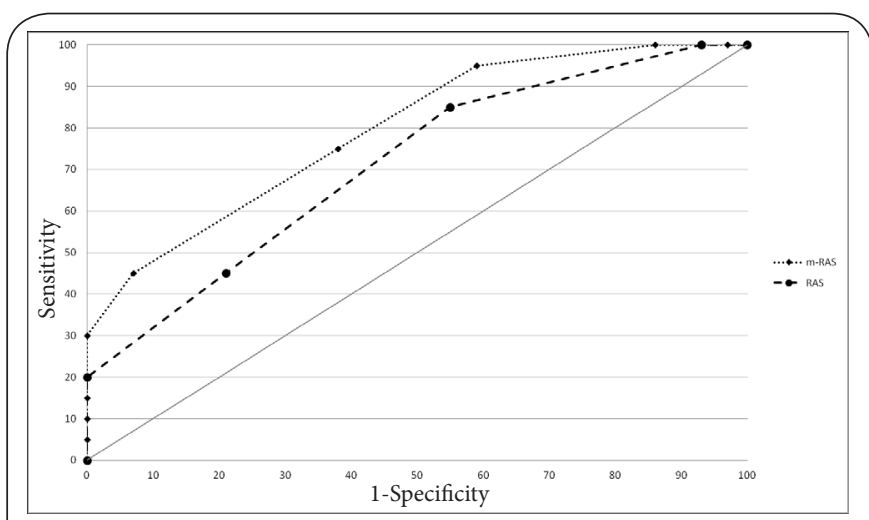

Figure 3. ROC curve for predicting day $3 \mathrm{~S} / \mathrm{F}$ ratio of $<445$ using day $1 \mathrm{x}$-ray scores.

Other data for the group not requiring oxygen but with $\mathrm{SpO}_{2}$ $<94 \%$ is shown in (Table 1 ).

\section{Discussion}

This study has evaluated a new system for assessing atelectasis on chest $x$-ray of patients following cardiac surgery. The overall incidence of atelectasis on return to ICU following cardiac surgery was found to be $86 \%$. This is comparable with other studies in this population which have reported an incidence of $64 \%$ to $100 \%$ [13-15].

The m-RAS was developed to address perceived deficiencies when scoring atelectasis on CXRs of patients undergoing cardiac surgery. This study has demonstrated that day $1 \mathrm{~m}$-RAS is more accurate than day 1 RAS in predicting poor oxygenation in postoperative cardiac surgical patients from their routine CXRs. We hypothesise that this improved predictive ability is due to the ability of $\mathrm{m}$-RAS to better differentiate subtotal lobar atelectasis.

The selection of appropriate end-points for Phase II clinical trials is essential to robust study design but may prove problematic. Defining a clinically important end point in studies of critically ill patients is an important consideration in order to avoid 
Parke et al. Medical Imaging and Radiology 2014,

http://www.hoajonline.com/journals/pdf/2054-1945-2-2.pdf

doi: 10.7243/2054-1945-2-2

poorly conceived clinical trials [16]. Whilst designing a study to investigate the effects of nasal high flow oxygen therapy on atelectasis in patients following cardiac surgery, [9] we were tasked with finding a suitable tool to measure, accurately, atelectasis on chest $\mathrm{x}$-ray at various time points postoperatively. It was felt that published scoring systems may over-estimate the severity of subtotal bilateral basal atelectasis frequently seen following cardiac surgery, thus reducing the specificity of the scores ability to predict clinically important indices. Therefore, a system was designed to more accurately describe the degree of atelectasis formation recognizing changes throughout the whole lung and with the ability to differentiate between patients with bilateral changes affecting the lower lobes only and patients with more extensive changes. Other published trials have faced this problem too, describing inconsistencies in the way atelectasis is reported and the apparent lack of an adequately validated scoring system for assessment and reporting of atelectasis $[12,14]$.

Previous studies differ in how atelectasis is perceived to affect oxygenation. One study found that hypoxaemia was not present in most patients who had demonstrated atelectasis, with only $4 \%$ being unable to maintain an arterial oxygen tension of $13.3 \mathrm{kPa}$ [14] while another reports that the presence of atelectasis coincided with a requirement for higher positive end expiratory pressure (PEEP) and $\mathrm{FiO}_{2}$ necessary to maintain oxygenation [17]. In this study it was found that the day $1 \mathrm{~m}$-RAS was a good predictor of an $\mathrm{S} / \mathrm{F}$ ratio of below 445 which would identify patients on supplemental oxygen therapy or those who had an $\mathrm{SpO}_{2}<94 \%$ on day 3. This is a relevant and pragmatic clinical outcome for this group and reflects guidelines in the management of oxygen therapy in critically ill adults [18].

This study also demonstrated a difference in the temporal relationship between clinical signs (e.g. respiratory rate and oxygen saturations) and the changes seen on chest $x$-ray. This concept of a time-lag between clinical changes and CXR changes is well described. Clinical examination has been found to under-estimate the frequency of atelectasis and changes in temperature, heart rate and respirations are poorly correlated with atelectasis post cardiopulmonary bypass $[\mathbf{1 4 , 1 9 ]}$. Changes in lung function have been described previously with evidence showing that pulmonary complications persist for around a week after cardiac surgery, with the most severe symptoms observed around the second post-operative day [20-22]. Increased elastance parameters following cardiac surgery with peak changes occurring around day two to three have also been demonstrated [22].

\section{Limitations of this study}

No assessment of atelectasis was performed on the preoperative chest $x$-ray, therefore the assumption is that there was no pre-operative atelectasis. Pre-operative CXR assessment has not been routinely performed in previously published studies either. One study took pre-operative x-rays and compared them to post-operative and found none at baseline but $8 / 35$ had atelectasis post-operatively [22].

No other demographic or clinical data was collected. This study was performed purely to assess the degree of atelectasis on chest $\mathrm{x}$-ray and to determine how this might predict oxygenation status post-operatively.

This study was designed as a retrospective study, thus potentially suffering from selection bias. However to minimize selection bias the protocol required the enrollment of 50 consecutive patients who met the inclusion and exclusion criteria chosen for this study who received routine postoperative oxygen therapy. They should therefore reflect the group that will be enrolled into the planned randomized controlled trial.

\section{Conclusion}

This new scoring method appears to be better suited as an outcome measure of atelectasis in studies of patients following cardiac surgery. It may also have some utility in discriminating patients who require ongoing supplemental oxygen on postoperative day 3 , however further prospective studies are required to confirm this. We propose to use this modified scoring system as a secondary outcome in a randomised controlled trial investigating the use of prophylactic nasal high flow oxygen therapy after cardiac surgery (www.ANZCTR. org.au/) ACTRN12610000973011 [9].

\section{Competing interests}

The authors declare that they have no competing interests.

\section{Authors' contributions}

\begin{tabular}{|l|c|c|c|c|}
\hline Authors' contributions & RLP & SPM & DM & AJ \\
\hline Research concept and design & $\checkmark$ & $\checkmark$ & $\checkmark$ & $\checkmark$ \\
\hline Collection and/or assembly of data & $\checkmark$ & -- & $\checkmark$ & -- \\
\hline Data analysis and interpretation & $\checkmark$ & -- & -- & -- \\
\hline Writing the article & $\checkmark$ & $\checkmark$ & $\checkmark$ & $\checkmark$ \\
\hline Critical revision of the article & $\checkmark$ & $\checkmark$ & $\checkmark$ & $\checkmark$ \\
\hline Final approval of article & $\checkmark$ & $\checkmark$ & $\checkmark$ & $\checkmark$ \\
\hline Statistical analysis & $\checkmark$ & -- & -- & -- \\
\hline
\end{tabular}

\section{Acknowledgement}

With thanks to Professor Chris Triggs and Kai Xiong, Department of Statistics, The University of Auckland. This study is part of a programme of research partly funded by the Health Research Council of New Zealand and the Green Lane Research and Education Fund. Research in the CVICU is partially funded by an unrestricted grant from Fisher and Paykel Healthcare, New Zealand.

\section{Publication history}

Editor: Maythem Saeed, University of California, San Francisco, USA.

Received: 28-Oct-2013 Accepted: 21-Feb-2014

Published: 03-Mar-2014

\section{References}

1. Zarbock A, Mueller E, Netzer S, Gabriel A, Feindt P and Kindgen-Milles 
Parke et al. Medical Imaging and Radiology 2014,

D. Prophylactic nasal continuous positive airway pressure following cardiac surgery protects from postoperative pulmonary complications: a prospective, randomized, controlled trial in $\mathbf{5 0 0}$ patients. Chest. 2009; 135:1252-9. | Article | PubMed

2. Sidebotham D, McKee A, Gillham M and Levy J. Cardiothoracic Critical Care. Philadelphia: Butterworth Heinemann Elsevier; 2007.

3. Lumb AB, Greenhill SJ, Simpson MP and Stewart J. Lung recruitment and positive airway pressure before extubation does not improve oxygenation in the post-anaesthesia care unit: a randomized clinical trial. Br J Anaesth. 2010; 104:643-7. | Article | PubMed

4. Joshi $P$, Fraser JF and Mullany DV. The high risk cardiac surgical patient. Curr Anaesth Crit Care. 2005; 16:369-83. | Article

5. Pasquina P, Merlani P, Granier JM and Ricou B. Continuous positive airway pressure versus noninvasive pressure support ventilation to treat atelectasis after cardiac surgery. Anesth Analg. 2004; 99:1001-8. | Article I PubMed

6. Kavanagh BP. Perioperative atelectasis. Minerva Anestesiol. 2008; 74:2857. | Article | PubMed

7. Magnusson $L$ and Spahn DR. New concepts of atelectasis during general anaesthesia. Br J Anaesth. 2003; 91:61-72. | Article | PubMed

8. Eastwood GM, O'Connell B and Considine J. Oxygen delivery to patients after cardiac surgery: a medical record audit. Crit Care Resusc. 2009; 11:238-43. | Article | PubMed

9. Parke RL, McGuinness SP, Dixon R and Jull A. Protocol for a randomised controlled trial of nasal high flow oxygen therapy compared to standard care in patients following cardiac surgery: the HOT-AS study. Int J Nurs Stud. 2012; 49:338-44. | Article | PubMed

10. Richter Larsen K, Ingwersen $U$, Thode S and Jakobsen S. Mask physiotherapy in patients after heart surgery: a controlled study. Intensive Care Med. 1995; 21:469-74. I Article I PubMed

11. Wilcox P, Baile EM, Hards J, Muller NL, Dunn L, Pardy RL and Pare PD. Phrenic nerve function and its relationship to atelectasis after coronary artery bypass surgery. Chest. 1988; 93:693-8. I Article I PubMed

12. Hendriks $T$, de Hoog M, Lequin MH, Devos AS and Merkus PJ. DNase and atelectasis in non-cystic fibrosis pediatric patients. Crit Care. 2005; 9:R351-6. | Article | PubMed Abstract | PubMed Full Text

13. Westerdahl E, Lindmark B, Eriksson T, Hedenstierna $G$ and Tenling A. The immediate effects of deep breathing exercises on atelectasis and oxygenation after cardiac surgery. Scand Cardiovasc J. 2003; 37:363-7. | Article | PubMed

14. Gale GD, Teasdale SJ, Sanders DE, Bradwell PJ, Russell A, Solaric B and York JE. Pulmonary atelectasis and other respiratory complications after cardiopulmonary bypass and investigation of aetiological factors. Can Anaesth Soc J. 1979; 26:15-21. I Article I PubMed

15. Tenling A, Hachenberg T, Tyden H, Wegenius $G$ and Hedenstierna $G$. Atelectasis and gas exchange after cardiac surgery. Anesthesiology. 1998; 89:371-8. | Article | PubMed

16. McAuley DF, O'Kane C and Griffiths MJ. A stepwise approach to justify phase III randomized clinical trials and enhance the likelihood of a positive result. Crit Care Med. 2010; 38:S523-7. I Article I PubMed

17. Verheij J, van Lingen A, Raijmakers PG, Spijkstra JJ, Girbes AR, Jansen EK, van den Berg FG and Groeneveld AB. Pulmonary abnormalities after cardiac surgery are better explained by atelectasis than by increased permeability oedema. Acta Anaesthesiol Scand. 2005; 49:1302-10. | Article I PubMed

18. O'Driscoll BR, Howard LS and Davison AG. BTS guideline for emergency oxygen use in adult patients. Thorax. 2008; 63 Suppl 6:vi1-68. | Article I PubMed

19. Gale GD and Sanders DE. The Bartlett-Edwards incentive spirometer: a preliminary assessment of its use in the prevention of atelectasis after cardio-pulmonary bypass. Can Anaesth Soc J. 1977; 24:408-16. I Article I PubMed

20. Jenkins SC, Soutar SA, Forsyth A, Keates JR and Moxham J. Lung function after coronary artery surgery using the internal mammary artery and the saphenous vein. Thorax. 1989; 44:209-11. | Article | PubMed Abstract | PubMed Full Text

21. Taggart DP. Respiratory dysfunction after cardiac surgery: effects of avoiding cardiopulmonary bypass and the use of bilateral internal mammary arteries. Eur J Cardiothorac Surg. 2000; 18:31-7. | Article | PubMed

22. Albu G, Babik B, Kesmarky K, Balazs M, Hantos Z and Petak F. Changes in airway and respiratory tissue mechanics after cardiac surgery. Ann Thorac Surg. 2010; 89:1218-26. | Article | PubMed

Citation:
Parke RL, McGuinness SP, Milne D and Jull A. A
new system for assessing atelectasis on chest x-ray
after sternotomy for cardiac surgery. Med Imaging
Radiol. 2014; $2: 2$.
http://dx.doi.org/10.7243/2054-1945-2-2

Citation:

Parke RL, McGuinness SP, Milne D and Jull A. A new system for assessing atelectasis on chest $\mathrm{x}$-ray after sternotomy for cardiac surgery. Med Imaging http://dx.doi.org/10.7243/2054-1945-2-2 